\title{
Motor Proficiency and Body Mass Index of Preschool Children: In Relation to Socioeconomic Status
}

\author{
Özgür Mülazımoğlu-Ballı \\ Correspondence: Özgür Mülazımoğlu-Ballı, Faculty of Sport Sciences, Pamukkale University Kınıklı Campus, \\ 20020-Denizli, Turkey
}

Received: January 14, 2016 Accepted: January 28, 2016 Online Published: February 23, 2016

doi:10.11114/jets.v4i4.1302 URL: http://dx.doi.org/10.11114/jets.v4i4.1302

\begin{abstract}
The aim of the study was to investigate the correlation between motor proficiency and body mass index and to assess the socioeconomic status differences in motor proficiency and body mass index of preschool children. Sixty preschool children in the different socioeconomic status areas of central Denizli in Turkey participated in the study. The Bruininks-Oseretsky Test of Motor Proficiency, Second Edition (BOT-2) was used to assess children's motor proficiency and height/weight measurements were taken to calculate the BMI of children. There was no significant relationship between BOT-2 scores and body mass index scores of preschool children ( $p>0.05)$. There were significant SES differences in favor of high and middle socioeconomic status preschool children $(p<0.05)$. Low socioeconomic status children had lower manual coordination, body coordination, strength and agility and total BOT-2 composite scores than their high and middle counterparts. The teachers, parents or those responsible for low socioeconomic status children in particular, have to find a way of practicing and improving the fundamental motor skills of preschool children.
\end{abstract}

Keywords: BMI, motor proficiency, preschool children, SES

\section{Introduction}

Childhood and adolescent inactivity and obesity are important problems of our time. In the literature a lot of studies can be found relating to the relationship between physical activity level, display of inactivity, and body mass index (BMI, a reliable indicator of body fat/obesity) (Trost, Sirard, Dowda, Pfeiffer, \& Pate, 2003; Vale et al., 2011). It is known that as people become obese, they tend not to participate in physical activity or people become obese because they are inactive; this is a vicious cycle. No matter which the cause or reason, a significant amount of research indicates that a lower level of physical activity is positively correlated with higher body fat (Trost et al, 2003; Trost, Kerr, Ward, \& Pate, 2001; Wrotniak, Epstein, Dorn, Jones, \& Kondilis, 2006). Aside from childhood and adolescent periods, researchers today are curious about preschool physical activity levels and the BMI relationship, (as BMI in preschool years could be an indicator for childhood/adolescent obesity and inactivity) (Whitaker, Wright, Pepe, Seidel, \& Dietz, 1997) and also BMI and motor skills which have a positive correlation with physical activity (Fisher et al., 2005; Laukkanen, Pesola, Havu, Sääkslahti, \& Finni, 2014; Wrotniak et al., 2006). A motor skill can be defined as "a common underlying process of gaining control in voluntary movement of the body, limbs and/or head" (Gallahue \& Ozmun, 2006). If children are not good at using fundamental motor skills (FMS) (such as; running, jumping, throwing, standing on one foot etc.), it could be that they are more physically inactive at preschool age, which may then increase their obesity level in the future (Stodden et al., 2008). Some researches indicate that there are negative correlations between motor skill proficiency and BMI of children (D'Hondt, Deforche, De Bourdeaudhuij, \& Lenoir, 2009; Graf et al., 2004; Lopes, Stodden, Bianchi, Maia, \& Rodrigues, 2012; Siahkouhian, Mahmoodi, \& Salehi, 2011). Conversely, other studies have shown that there is no correlation between BMI and the motor proficiency level of preschool children (Logan, Scrabis-Fletcher, Modlesky, \& Getchell, 2011; Nevrik et al., 2011). In the literature there are few studies relating to preschool children, BMI and motor proficiency; and as can be seen, these studies have conflicting results. There are, however, several other reasons that may affect the motor proficiency of children, such as nutrition, illness, physical activity participation, social conditions.

Children carry out motor acts in a social contex (e.g., at home, at play and at school) that places specific demands on the motor competencies and physical activity of infants, children and adolescents (Malina et al., 2004). Social conditions include family size, area of residence, overall socioeconomic conditions etc. Variation in lifestyle associated with social 
class is often viewed in the context of socioeconomic status (SES) (Malina et al., 2004) which refers to a grouping of people who have similar economic, educational, and occupational characteristics (Gabbard, 2014). In other words, SES includes income, educational level and occupation of parents, and neighborhood of residence (Malina et al., 2004). As such, due to low SES, children's motor development may be affected. Although research on this topic gravely lacking, it appears that children from low income families may be limited in motor development experiences due to at least in part a lack of financial resourses, parental involvement time, and the parental experience (Gabbard, 2014; Goodway \& Smith, 2005). In addition, they may not have the opportunities to move freely or to act as much as they want due to the unsuitable environment of their resident neigbourhood. All of these factor potentially important factors should be considered regarding children's motor performance (Malina et al., 2004). Children who come from a lower SES background may have less access to organized sport and physical activity, particularly those sports that require expensive equipment (ice hockey) or lessons (figure skating, tennis) and extensive time commitments (Haywood \& Getchell, 2005). As a result, these children may not gain experiences and practice related to these particular activities. Previous researches has shown that, in general, low SES children have a low motor proficiency level (Chowdhury, Wrotniak, \& Ghosh, 2010; D’Hondt et al., 2009; Hardy, Reinten-Reynolds, Espinel, Zask, \& Okely, 2012; Mészáros et al., 2008; Okely \& Booth, 2004). In literature, there were limited studies related to the SES of preschool children.

As there were few studies related to preschool children's motor proficiency levels and the relationships of related factors such as BMI, SES etc., we need to test the relationships of these factores with motor proficiency. In the literature, motor proficiency levels of children were shown by using mostly gross motor development tests. In this study participants' not only gross motor, but also fine motor control and coordination, body coordination and strength and agility motor proficiency level were tested. Interestingly, many researchers have conducted studies with elementary school children where the status of pre-school children was ignored. Consequently, the primary purpose of this study was to investigate the correlation between motor proficiency and BMI of preschool children; and also to test SES differences in motor proficiency and the BMI of children.

\section{Materials and Methods}

\subsection{Participants}

Participants of this study were 60 preschool children (34 girl, 26 boy with $\mathrm{M}_{\mathrm{Age}}=72.98 \pm 3.75$ ) from 3 different primary schools preschool classes in different SES regions of central Denizli in Turkey. Eleven children were in low SES school, 25 in middle and 24 in high SES schools. Some participants were not at school while weight and height measurements were taken for BMI; therefore in this study a total of 32 girls and 20 boys, numbering 52 children in all had BMI scores assessed.

\subsection{Data Collection Instruments}

\subsubsection{Motor Proficiency Measurement}

The Bruininks-Oseretsky Test of Motor Proficiency, Second Edition (BOT-2) was used to assess childrens motor proficiency. BOT-2 is an individually-administered test that uses engaging, goal-directed activities to measure a wide array of motor skills in individuals aged 4 through 21 (Bruininks \& Bruininks, 2005). The BOT-2 assesses motor proficiency in four motor-area composites; fine manual control (FMC), manual coordination (MC), body coordination (BC) and strength and agility (SA). BOT-2 has 8 subtests with 53 items and each motor-area composite has two subtests. The total motor composite score can be calculated by adding four composite scores together (53 items, 8 subtests and 4 four motor-area composites; score range $=0-320$ points) (Bruininks and Bruininks, 2005).

BOT-2 for the subtests, motor-area composites and total composite score internal consistency (for $5,6 \& 7$ years olds) ranged from $0.73-0.90$, test-retest coefficients over an interval of 7-42 days (for ages 4-7) ranged from 0.47 to 0.91 , and inter-rater reliability coefficients (for ages 4-7) ranged from 0.84 to 0.99 (Bruininks \& Bruininks, 2005). For the present study BOT-2 motor-area composites and total composite score internal consistency (for 6 years olds) ranged from $0.67-0.86$.

\subsubsection{Body Mass Index (BMI)}

BMI, a reliable indicator of body fat for most children and teens, is a number calculated from a child's weight and height $[\mathrm{BMI}=$ Weight $(\mathrm{kg}) \div($ Height $\mathrm{m}) 2]($ Centers for Disease Control and Prevention [CDCP], 2014). Height $(\mathrm{cm})$ and weight $(\mathrm{kg})$ were measured according to standard procedures that height was measured with the child in a standard erect posture, without shoes and weight were measured with the child attired in ordinary, indoor clothing without shoes (Malina et al., 2004).

\subsubsection{Socioeconomic Status (SES)}

SES was determined from the official records of the Denizli Provincial Directorate of National Education. According to 
the data, three schools were chosen from different socio-economical areas in Denizli, Turkey. After selection of the school, factors that reflect the SES of the area (such as rental rates within the school neighbourhood, access to social facilities, family household income etc.) were also examined in order to establish the SES school classification of the school SES in this study. SES was classified into three categories: high, medium and low.

In Turkey, a child, who wants to go to the public schools, has to choose schools in the same neighborhood in his/her house. Because of this reason, the classification made in this study was considered to reflect the three different SES.

\subsection{Procedure}

Permission was obtained from the Ministry of National Education (Turkey) to conduct this study on children in schools. Before administrating the tests, the purpose of the study and their rights as participants, was explained to the children by researcher. Firstly the children's weight and height measurements were taken and then the BOT-2 was administered to children. For each test item, the researcher taught the task and then observed the child's performance to determine a raw score based on standardized criteria.

\subsection{Data Analysis}

For the BOT-2 test items, raw performance scores on each different BOT-2 item were converted into point scores according to the procedure in the BOT-2 test manual. Adding these individual point scores together, subtests total and total BOT-2 point score were obtained. To determine which statistical analysis would be used, the Kolmogrov Smirnov test was implemented to BOT-2 point scores and for the BMI of children for SES groups and gender. The Kolmogrov Smirnov test was used because the number of participants of each sex and different SES group was below fifty. Results showed that the childrens BOT-2 strength and agility composite in girls, manual coordination in middle and low SES groups, BMI of boys and BMI in low and high SES groups scores did not have a normal distribution $(\mathrm{p}<0.05)$. Hence, non-parametric analyses were used.

For the data analysis descriptive statistics, the Spearman Brown correlation analysis, the Mann-Whitney U and the Kruskal-Wallis $\mathrm{H}$ tests were used. When testing hypotheses, a 0.05 significant level was used. To determine the relationship of BOT-2 and the BMI of preschool children, a Spearman Brown correlation was applied. Differences in BOT-2 and the BMI of preschool children in different SES groups (low, middle and high) were found by using the Kruskal-Wallis $\mathrm{H}$ test. To establish the mean rank differences of BOT-2 and BMI scores of preschool children, a Mann-Whitney U test was conducted for each significant difference.

\section{Results}

All participants were included in the statistical analysis based on gender and SES. Participants' mean BOT-2 motor-area and total motor composite scores, BMI scores and standard deviations are presented in Table 1.

Table 1. BOT-2 motor-area and total motor composite scores and BMI scores and standard deviations according to gender and SES of preschool children.

\begin{tabular}{|c|c|c|c|c|c|c|c|c|c|c|c|c|}
\hline & \multicolumn{4}{|c|}{ Sex } & \multicolumn{6}{|c|}{ SES } & \multicolumn{2}{|c|}{ Total } \\
\hline & \multicolumn{2}{|c|}{ Girl } & \multicolumn{2}{|c|}{ Boy } & \multicolumn{2}{|c|}{ Low } & \multicolumn{2}{|c|}{ Middle } & \multicolumn{2}{|c|}{ High } & \multirow[b]{2}{*}{ M } & \multirow[b]{2}{*}{ SD } \\
\hline & M & SD & M & SD & M & SD & M & $\mathrm{SD}$ & M & SD & & \\
\hline FMC & 55.65 & 10.85 & 52.35 & 11.36 & 53.00 & 11.69 & 53.04 & 11.17 & 56.00 & 11.00 & 54.22 & 11.10 \\
\hline MC & 34.12 & 7.95 & 36.69 & 7.64 & 27.64 & 7.15 & 35.04 & 6.73 & 38.92 & 6.85 & 35.23 & 7.85 \\
\hline $\mathrm{BC}$ & 42.44 & 8.69 & 40.15 & 6.03 & 29.27 & 4.34 & 43.48 & 5.25 & 44.92 & 5.13 & 41.45 & 7.68 \\
\hline SA & 39.32 & 7.25 & 39.39 & 5.88 & 29.36 & 4.68 & 41.88 & 5.15 & 41.29 & 4.14 & 39.35 & 6.64 \\
\hline BOT-2 Total & 171.53 & 26.13 & 168.58 & 19.32 & 139.27 & 20.27 & 173.44 & 17.47 & 181.13 & 17.34 & 170.25 & 23.29 \\
\hline BMI & 16.12 & 1.82 & 16.56 & 2.23 & 16.35 & 2.74 & 16.19 & 1.68 & 16.37 & 2.00 & 16.29 & 1.98 \\
\hline
\end{tabular}

Abbreviations: SES = socioeconomic status, $\mathrm{FMC}=$ fine manual control, $\mathrm{MC}=$ manual coordination, $\mathrm{BC}=$ body coordination, $\mathrm{SA}=$ strength and agility, BOT-2 $=$ The Bruininks-Oseretsky Test of Motor Proficiency (Second Edition), BMI $=$ body mass index

For testing the relationship between BOT-2 and BMI, a Spearman Brown correlation was computed between the BOT-2 scores and BMI scores for preschool children. None of the correlation of preschool children's BOT-2 sub-test scores and BMI were found to be significant ( $p>0.05$ ). Results of the Spearman Brown correlation analyses are presented in Table 2. 
Table 2. Results of BOT-2 and BMI scores, Spearman Brown correlations scores of preschool children.

\begin{tabular}{llllll}
\hline & BOT -2 & & & \\
& FMC & MC & BC & SA & Total \\
\hline BMI & 0.100 & 0.184 & -0.044 & -0.179 & 0.054
\end{tabular}

Abbreviations: BOT-2 $=$ The Bruininks-Oseretsky Test of Motor Proficiency (Second Edition), FMC $=$ fine manual control, $\mathrm{MC}=$ manual coordination, $\mathrm{BC}=$ body coordination, $\mathrm{SA}=$ strength and agility, $\mathrm{BMI}=$ body mass index

To investigate SES differences on BOT-2 and BMI, the Kruskal-Wallis H test was applied to the data. Table 3 shows the results of the Kruskal-Wallis $\mathrm{H}$ test.

Table 3. Kruskal-Wallis H test results of preschool childrens' BOT-2 and BMI scores according to SES:

\begin{tabular}{|c|c|c|c|c|c|c|c|}
\hline & SES & $\mathrm{n}$ & Mean Rank & $\mathrm{df}$ & $X^{2}$ & $\mathrm{p}$ & $\begin{array}{l}\text { Significant } \\
\text { Difference }\end{array}$ \\
\hline \multirow{3}{*}{ FMC } & $\mathrm{L}$ & 11 & 29.95 & 2 & 0.797 & 0.671 & \\
\hline & M & 25 & 28.46 & & & & \\
\hline & $\mathrm{H}$ & 24 & 32.88 & & & & \\
\hline \multirow[t]{3}{*}{ MC } & $\mathrm{L}$ & 11 & 14.09 & 2 & 15.424 & 0.000 & L-M, \\
\hline & M & 25 & 29.62 & & & & $\mathrm{M}-\mathrm{H}$ \\
\hline & $\mathrm{H}$ & 24 & 38.94 & & & & \\
\hline \multirow[t]{3}{*}{$\mathrm{BC}$} & $\mathrm{L}$ & 11 & 6.27 & 2 & 26.965 & 0.000 & L-M, L-H \\
\hline & M & 25 & 33.62 & & & & \\
\hline & $\mathrm{H}$ & 24 & 38.35 & & & & \\
\hline \multirow[t]{3}{*}{ SA } & $\mathrm{L}$ & 11 & 7.68 & 2 & 23.396 & 0.000 & L-M, L-H \\
\hline & M & 25 & 36.98 & & & & \\
\hline & $\mathrm{H}$ & 24 & 34.21 & & & & \\
\hline \multirow[t]{3}{*}{ BOT-2 Total } & $\mathrm{L}$ & 11 & 9.09 & 2 & 21.908 & 0.000 & L-M, L-H \\
\hline & M & 25 & 32.16 & & & & \\
\hline & $\mathrm{H}$ & 24 & 38.58 & & & & \\
\hline \multirow[t]{3}{*}{ BMI } & $\mathrm{L}$ & 9 & 25.22 & 2 & 0.111 & 0.946 & \\
\hline & M & 22 & 27.18 & & & & \\
\hline & $\mathrm{H}$ & 21 & 26.33 & & & & \\
\hline
\end{tabular}

Abbreviations: $\mathrm{SES}=$ socioeconomic status, $\mathrm{FMC}=$ fine manual control, $\mathrm{MC}=$ manual coordination, $\mathrm{BC}=$ body coordination, SA $=$ strength and agility, BOT- $2=$ The Bruininks-Oseretsky Test of Motor Proficiency (Second Edition), BMI = body mass index

$\mathrm{p}<0.05$

The results indicate that BOT- $2 \mathrm{MC}, \mathrm{BC}, \mathrm{SA}$ and Total composite scores have significant difference according to SES $(\mathrm{p}<0.05)$, but there is no significant differences on BOT-2 FMC and BMI scores ( $p>0.05)$. To find out the mean rank differences of BOT-2 scores of preschool children, the Mann-Whitney U test was conducted on BOT- 2 scores. In BOT-2 manual coordination, composite scores the low SES group had a significantly lower mean rank than both the middle and high SES group. Also the middle SES group had a significantly lower mean rank than the high SES group. In all other BOT-2 scores (BC, SA and total BOT-2 scores) the low SES group had significantly the lowest mean rank than both the middle and high SES groups.

\section{Discussion}

The present study firstly examines the correlation between motor proficiency and BMI in preschool children. Although some studies are indicated that low negative correlations between motor proficiency and the BMI of 4-6 years old children (D'Hondt et al., 2009; Lopes et al., 2012; Wrotniak et al., 2006), this study results are in line with other studies which also demonstrate no relationship between motor proficiency and BMI (Logan et al., 2011; Nervik, Martin, Rundquist, \& Cleland, 2011; Saraiva, Rodrigues, Cordovil, \& Barreiros, 2013). All thsese conflicting results may indicate that BMI and motor proficiency correlation in preschool children not much strong as older children. Saraiva et al. (2013) indicated that instead of somatic measueres such as BMI, age was more predictive of preschoolers' motor development. Some reasearcher make an alterantive explantion by grouping BMI and motor proficiency percentile and they indicated that when children classified as "overweight/obese" by their BMI percentiles did rank significantly lower in their motor proficiency percentiles than their peers (Logan et al., 2011; Nervik et al., 2011). As in this study all most all participants were normal or healthy weight percentile (CDCP, 2014), it might affect not to find the relationship between BMI and motor proficiency.

The secondary purpose of this study was the examine SES differences in motor proficiency and the BMI of children. Similar to Drenowatz et al. (2010)'s study, there was no significant difference in the BMI scores of the three different 
SES groups of preschool children and also indicated that when the children get older, the SES difference in BMI arises that lower SES children (9-10 years old) had higher body mass and BMI compared to higher SES groups. When the BOT-2 scores were tested for SES differences, results varied according to the different sub-tests. There was no significant difference in the BOT-2 FMC scores of three different SES groups. Unlike the present study, Bobbio, Morcillo, Barros and Concalves (2007) stated that children attending public state schools had a 5.5-fold greater risk of having inadequate fine motor skills for their age, compared to children attending private schools. However, Krombholz (2006) in his study, partially support the results of the current study.

On the other hand, data analysis has showed that there were significant differences in other scores of the different SES groups. In the BOT-2 MC, BC, SA and total scores, the low SES group had a significantly lower mean rank than both the middle and high SES group. Chowdhury et al. (2010) reported that Indian children of higher SES had a higher score for motor development than lower SES counterpart. Similarly, some researchers stated that girls with low SES were less competent in locomotor skills compared with their high SES peers (Hardy et al., 2012; Mészáros et al., 2008). Although Okely and Booth (2004) specified that there was no consistent association between prevalence of skill mastery and SES, there was a positive association between SES and the kick and vertical jump for boys, and catch, dodge, and vertical jump for girls. Likewise, in their study, D'Hondt et al. (2009) identified that scores for manual dexterity, ball skills and total MABC were not significantly different between both two SES-groups, except regarding balance.

In the literature, researchers categorize social status sometimes according to income level of parents or parent's educational level or sometimes according to children participation in public or private preschools (Bobbio, et al., 2007; D'Hondt et al., 2009; Mészáros et al., 2008). In the present study all participants were from public schools but in different socio economic areas (different resident neighbourhoods). Almost all reaserchs show that motor proficiency and SES has a positive association. This indicates that low SES children have low motor proficiency and vice versa. Although all children in the study were from public schools, the schools' own physical capacity might have affected differences. On the other hand, participating in different physical activities, in particular (e.g. gymnastics, swimming, dance etc.) outside of school, might also determine these differences.

SES is a factor that influences access to many organized sports and club programmes, often at relatively young ages, in which children receive specialized instruction and practise under the guidance of trained coaches (Malina et al., 2004). High and middle SES children might have more opportunitiy to participate in these kinds of activities. Motor skill practice is useful to improve the FMS competence of children (Logan et al., 2011). According to the results of this study, it is important to create an environment for children to engage in different kinds of physical activities. As FMS are the the basis of the specialised skills employed in sports and other leisure activities, their development should be supported by parents and the school administrations. If children can not perform FMS efficiently and correctly, they may be more physically inactive in future life.

Limitations of this study include using official records for the SES of schools. The Denizli Provincial Directorate of National Education official records of school region were used. Moreover, if participants volunteered certain socio economic information (parental income level, residential house, renter/owner, etc.) this would provide further support for participant's SES. A final limitation was that the study sample size was small, but for the purposes of this study, it was large enough to discover significant differences.

In conclusion, this study examined the correlation between motor proficiency and the BMI in preschool children and also tested SES differences in motor proficiency and the BMI of preschool children. The main conclusions to be drawn are: (a) based on the sample of this study, there was no correlation between motor proficiency and the BMI of 6 year-old children (b) there was no significant difference in BMI and BOT-2 fine manual control scores of three different SES groups, but (c) that there were significant differences in the BOT-2 manual coordination, body coordination, strength \& agility and total score of different SES groups, in favour of high SES groups. As FMS have a significant effect on future organized sports and physical activities, it is important to give children more opportunity to practise these FMS and encourage them to participate in different physical activities, (especially children of low SES). In low SES areas, new FMS programs could possibly be developed utilising affordable materials, and, by this means, low-SES children may also achieve the same physical standards as their high SES counterparts.

\section{References}

Bobbio, T. G., Morcillo, A. M., Barros, F. A. A., \& Concalves, V. M. (2007). Factors associated with inadequate fine motor skills in Brazilian students of different socioeconomic status. Perceptual Motor Skills, 105(3 Pt2), 11871195. http://dx.doi.org/10.2466/PMS.105.4.1187-1195

Bruininks, R. H., \& Bruininks, B. D. (2005). Bruininks-Oseretsky Test of Motor Proficiency (BOT-2) (2nd Ed.). USA: AGS Publishing. 
Centers for Disease Control and Prevention. (2014). About BMI for children and teens. Retrieved from: http://www.cdc.gov/healthyweight/assessing/bmi/childrens_bmi/about_childrens_bmi.html\#What\%20is\%20B MI.

Chowdhury, S. D., Wrotniak, B. H., \& Ghosh, T. (2010). Nutritional and socioeconomic factors in motor development of Santal children of the Purulia district, India. Early Human Development, 86, 79-84. http://dx.doi.org/10.1016/j.earlhumdev.2010.08.029

D’Hondt, E., Deforche, B., De Bourdeaudhuij, I., \& Lenoir, M. (2009). Relationship between motor skill and body mass index in 5-10 year-old children. Adaptive Physical Activity Quarterly, 26, 21-37.

Drenowatz, C., Eisenmann, J. C., Pfeiffer, K. A., Welk, G., Heelan, K., Gentile, D., \& Walsh, D (2010). Influence of socio-economic status on habitual physical activity and sendentary behavior in 8-to 11 year old children. $B M C$ Public Health, 10, 214. http://dx.doi.org//10.1186/1471-2458-10-214

Fisher, A., Reilly, J. J., Kelly, L., Montgomery, C., Williamson, A., Paton, J. Y., \& Grant, S. (2005). Fundamental movement skills and habitual physical activity in young children. Medicine and Science in Sports and Exercise, 37, 684-688. http://dx.doi.org/10.1249/01.MSS.0000159138.48107.7D

Gabbard C. P. (2014). Lifelong Motor Development ( $6^{\text {th }}$ Ed). USA: Pearson.

Gallahue, D. L., \& Ozmun, J. C. (2006). Understanding Motor Development: Infants, Children, Adolescents, Adults. $6^{\text {th }}$ Edition. New York: The McGraw-Hill Companies.

Goodway, J. D., \& Smith, D. W. (2005). Keeping All Children Healthy: Challenges to Leading an Active Lifestyle for Preschool Children Qualifying for At-Risk Programs Family \& Community Health, 28, 142-155.

Graf, C., Koch, B., Kretschmann-Kandel, E., Falkowski, G., Christ, H., Coburger, S., Lehmacher, W., Bjarnason-Wehrens, B., Platen, P., Tokarski, W., Predel, H. G., \& Dordel, S. (2004). Correlation between BMI, leisure habits and motor abilities in childhood (CHILT-Project) International Journal of Obesity, 28, 22-26. http://dx.doi.org/10.1038/sj.ijo.0802428

Hardy, L. L, Reinten-Reynolds, T., Espinel, P., Zask, A., \& Okely, A. D. (2012). Prevalence and Correlates of Low Fundamental Movement Skill Competency in Children. Pediatrics, 130, e390-e398. http://dx.doi.org/10.1542/peds.2012-034

Haywood, K. M., \& Getchell, N. (2005). Life Span Motor Development $\left(4^{\text {th }}\right.$ Ed). USA: Human Kinetics.

Krombholz, H. (2006). Physical Performance in Relation to age, Sex, Birth Order, Social Class, and Sports Activities of Preschool Children. Perceptual Motor Skills, 102, 477-484. http://dx.doi.org/10.2466/PMS.102.2.477-484

Laukkanen, A., Pesola, A., Havu, M., Sääkslahti, A., \& Finni, T. (2014). Relationship between habitual physical activity and gross motor skills is multifaceted in 5- to 8-year-old children. Scandinavian Journal of Medicine and Science in Sports, 24(2), e102-110. http://dx.doi.org/10.1111/sms.12116

Logan, S. W., Scrabis-Fletcher, K., Modlesky, C., \& Getchell N. (2011). The Relationship between Motor Skill Proficiency and Body Mass Index in Preschool Children. Research Quarterly for Exercise and Sport, 82(3), 442-448. http://dx.doi.org/10.1080/02701367.2011.10599776

Lopes, V. P., Stodden, D. F., Bianchi, M. M., Maia, J. A. R., \& Rodrigues, L. P. (2012). Correlation between BMI and motor coordination in children. Journal of Science and Medicine in Sport, 15, 38-43. http://dx.doi.org/10.1016/j.jsams.2011.07.005

Malina, R. M., Bouchard, C., \& Bar-Or, O. (2004). Growth, Maturation, and Physical Activity (2 ${ }^{\text {nd }}$ Ed). USA: Human Kinetics.

Mészáros, Z., Mészáros, J., Szmodis, B. M., Pampakas, P., Osváth, P., \& Völgyi, E. (2008). Primary School Child Development - Issues of Socioeconomic Status. Kinesiology, 40(2), 153-161.

Nervik, D., Martin, K., Rundquist, P., \& Cleland, J. (2011). The Relationship Between Body Mass Index and Gross Motor Development in Children Aged 3 to 5, Years Pediatric Physical Therapy, 23, $144-148$. http://dx.doi.org/10.1097/PEP.0b013e318218d356

Okely, A. D., \& Booth, M. L. (2004). Mastery of Fundamental Movement Skills among Children in New South Wales: Prevalence and Sociodemographic Distribution. Jornal of Science and Medicine in Sport, 7(3), 358-372.

Saraiva, L., Rodrigues, L. P., Cordovil L., \& Barreiros J. (2013). Influence of age, sex and somatic variables on the motor performance of pre-school children. Annals of Human Biology, 40(5), 444-450. http://dx.doi.org/10.3109/03014460.2013.802012 
Siahkouhian, M., Mahmoodi, H., \& Salehi, M. (2011). Relationship between fundamental movement skills and body mass index in 7 to 8 year-old children. World Applied Scencesi Journal, 15(9), 1354-1360.

Stodden, D. F., Goodway, J. D., Langendorfer, S. J., Roberton, M. A., Rudisill, M. E., Garcia, C., \& Garcia, L. E. (2008). A Developmental Perspective on the Role of Motor Skill Competence in Physical Activity: An Emergent Relationship Quest, 60, 290-306. http://dx.doi.org/10.1080/00336297.2008.10483582

Trost, S. G., Kerr, L. M., Ward, D. S., \& Pate, R. R. (2001). Physical activity and determinants of physical activity. International Journal of Obesity, 25, 822-829.

Trost, S. G., Sirard, J. R., Dowda, M., Pfeiffer, K. A., \& Pate, R. R. (2003). Physical activity in overweight and nonoverweight preschool children. International Journal of Obesity, 27, 834-839. http://dx.doi.org/10.1038/sj.ijo.0802311

Vale, S., Santos, R., Silva, P., Soares-Miranda, L., \& Mota, J. (2011). Relationship of objective measurement of physical activity during school hours and BMI in preschool children. International Journal of Pediatric Obesity, 6(S2), 37-38. http://dx.doi.org/ 10.3109/17477166.2011.613663

Whitaker, R. C., Wright, J. A., Pepe, M. S., Seidel, K. D., \& Dietz, W. H. (1997). Predicting obesity in young adulthood from childhood and parental obesity. The New England Journal of Medicine, 337, 869-873. http://dx.doi.org/10.1056/NEJM199709253371301

Wrotniak, B. H., Epstein, L. H., Dorn, J. M., Jones, K. E., \& Kondilis, V. A. (2006). The relationship between motor proficiency and physical activity in children. Pediatrics, 118, e1758-e1765. http://dx.doi.org/10.1123/jpah.2013-0398

This work is licensed under a Creative Commons Attribution 3.0 License. 